\title{
The Impact of Topic Congruence on Second Language Reading Comprehension
}

\author{
Marzieh Sadeghpour (Corresponding Author) \\ School of Foreign languages, Azad University of Takestan \\ Takestan, Qazvin, Iran \\ E-mail: Marziehsadeghpour@gmail.com \\ Sayyed Mohammad Alavi \\ Department of English Language and Literature, University of Tehran, Iran \\ E-mail:mohammad.alavi@gmail.com \\ Accepted: 09-07-2013 \\ Published: 01-09-2013 \\ URL: http://dx.doi.org/10.7575/aiac.ijalel.v.2n.5p.213
}

Received: 10-06-2013

doi:10.7575/aiac.ijalel.v.2n.5p.213

\begin{abstract}
The present study scrutinized the impact of congruent topics on the quality of L2 reading comprehension. 56 Iranian advanced-level students read 2 texts on a controversial topic, one on the advantages of child gender selection, and the other on disadvantages. Quality analysis of immediate and delayed recall tasks, defined as the amount of high and lowlevel information recalled correctly, was performed by analysis of variance. Results revealed that topic congruence affected immediate recall of both high and low-level information, and also delayed recall of low-level information. Findings showed that the effect of congruent topics on reading recall was detrimental; participants recalled less information from the passage with congruent topic than a passage with incongruent topic. Outcomes of the study suggest that controversial topics should be selected more cautiously, because they may not truly reflect L2 readers' reading comprehension.
\end{abstract}

Keywords: congruent topic, L2 reading, readers' attitude, immediate recall, delayed recall

\section{Introduction}

Reading comprehension is a crucial part in the process of learning and teaching, and it is believed to be the most important skill for language learners (Farhadi et.al, 2006). There are various factors that affect reading comprehension and the reading process. Comprehension does not take place by only enough language knowledge; there are situations that although learners know the vocabulary and grammar of the texts, yet they are not able to comprehend the texts properly. Readers may not comprehend what the writer intended because of the factors other than language knowledge that influence the comprehension process.

There have been attempts to find out about the cognitive and affective variables that influence the comprehension process, but there has not been a clear unified answer for the problems. The aim of the present study was to find out if topic congruence, as a cognitive factor, influences the quality of reading comprehension both in immediate and delayed recalls. In the body of literature, there have been various studies on the impact of topic variables on reading comprehension (Asher, Hymel, and Wigfield, 1978; Kobayashi, 2009; Carrell, and Wise, 1998; Eidswick, 2010), but most studies are conducted in L1. Since L2 readers and reading comprehension are more sophisticated than L1, these studies may not be transferable to L2 context. Therefore, there is a need to study factors that affect understanding L2 texts.

\section{Topic congruence and reading comprehension}

There have always been attempts to define memory and recall in different fields. Psycholinguists have also tried to define memory in the field of language and language learning. Bartlett (1932) defined remembering as reconstruction of past on the basis of one's stored experiences rather than exact reproduction of what is kept in the mind previously. He also argued that although there is a general tendency to believe that remembering is like taking a picture of past events and storing them in mind to recall later exactly as they happened, memory recalls events by fragments stored and retrieved later in the memory. This reconstruction of meaning based on the stored knowledge, may be affected by learners' background knowledge and attitude. The effects of attitudes on memory have long been a controversial issue. In the literature, it has been hypothesized that congruent information, information congenial to readers' belief system, are bettered recalled than incongruent information (Feather; 1969, Eagly, Chaiken, Chen, and Shaw-Barnes; 1999). Maplass (1969) explained that congruent information is better recalled because people usually pay attention selectively, and more attention is paid to congruent information. Roberts (1985) meta-analysed 38 studies and found that the attitudes affect memory, although this effect is modest, and explained that in traditional version of selective recall human memory tend to recall congruent information better. According to Eagly, Chaiken, Chen, and Shaw-Barnes (1999), recalling is affected by background knowledge and attitudes toward a topic. They believed that human memory is selective in recalling information and recalls congruent information better and ignores incongruent information. They 
justified better congruent recalling by the explanation of traditional theorists that human memory tries to defend what it believed to be true, and they believed that people's believes make their schema and this schema affects understanding and recalling of information.

The impact of attitudes on recall of past memories can be different for immediate and delayed recall. Read and Rosson (1982) found that congruency of attitudes did not affect the immediate recall, but had an impact on delayed recall. They believed that memories become more congruent to attitude as the time passes. Reutzel and Hollingsworth (1991) showed that topic congruence did not influence the L1 immediate recall, but influenced delayed retention in a way that participants with incongruent believes recalled less information than participants who had congruent ideas with reading passages.

It is also said that the impact of attitudes on memory varies according to the readers' amount of knowledge about the reading topic. Wiley (1995) found that non-expert participants recalled information which were more consistent to their attitudes and those participants with higher background knowledge about the topics were less effected by test bias effect. He stated that learners who are less knowledgeable about the topic may use their own believes and attitudes to compensate this lack of knowledge and they may recall information more on the basis of what they have previously stored, or believed to be true. It was also found that when the reading topic was congruent with readers' prior belief systems, the details of the passages were overlooked (Lee, 2009). Incongruent topics, on the other hand, were motivating enough for these L2 readers to focus their attention and search for the information with low content value.

There are inconsistencies in the outcomes of the studies on the impact of memory on recall. These inconsistencies may be due to the "nature of learning paradigm"; in real life, human beings acquire information, but in conducted studies participants are asked to pay attention and read controversial texts (Roberts, 1985). Eagly, Kulesa, Chen, and Chaiken (2001), took a meta-analysis of 70 experiments on the effect of attitudes on memory. They found that most of the studies' outcome showed slightly better memory for congruent information than for incongruent information. They noted that these results have been inconsistently obtained, so they conducted an experiment with participants with opposing attitudes on an important social issue. In their experiment, congruent and incongruent information proved to be equally memorable. They believe that one reason for these inconsistencies in the previous studies' outcome is due to the mistaken belief that people avoid incongruent information, but by the experiment they conducted, they showed that participants tried to read incongruent information carefully and even tried to remember them to be able to defend their own believes.

\section{Assessment of Reading comprehension}

Finding out how well readers comprehend, has always been a challenge both in L1 and L2. Since comprehension of a reading is a cognitive process, and the product is usually the only available source of assessment, assessing reading comprehension is not an easy task. Fletcher (2006) believes that since the nature of reading comprehension is multidimensional and complicated, measuring comprehension is not an easy task, and should not be a one dimensional approach.

Farhadi et.al (2006) state that although there are various methods for assessing comprehension of readers, yet there is no single accepted method that is accepted by all experts. One of the suggested ways in literature for assessing reading comprehension is free-recall task. Free recall task is used more in conducted researches than in the tests for evaluating comprehension of readers, because it measures comprehension of readers more than their inferences or language knowledge (Chang, 2006). However, Alderson (2000) criticizes free recall tasks for they may not reflect comprehension of readers truly because of the effects of the memory on recall. He states that a reader may read and comprehend a text, but cannot recall all understood because of poor memory.

Results of different studies have shown that the method of assessing reading comprehension influences how readers perform on a test of reading comprehension (Wolf, 1993).Free recall task like any other kind of testing instrument, has its own advantages and disadvantages, but since students are not limited by the pre-determined and designed tasks, they can show their comprehension much better in free recall tasks. So, in this study, for assessing the effect of topic congruence on the quality of reading comprehension of L2 learners, free recall tasks, as a kind of direct and integrative assessment task, were used.

\section{Research question}

The research question addressed in this study was: Does topic congruence influence the quality of L2 reading comprehension of Iranian advanced-level learners measured by immediate and delayed free recall tasks? Since there have been contrasting findings on the impact of congruent topics on the quality of reading comprehension, it was hypothesised that congruent and incongruent topics affect immediate and delayed recall of both high and low-level information.

\section{Method}

\subsection{Participants}

This study was conducted with 56 participants, 32 female and 24 male students, who studied TEFL and English literature at MA level. Participants were selected from 88 participants. 32 participants' data were excluded from analysis because 21 participants did not take part in the second session of data collection, 8 participants did not fill all the required forms, and 3 participants did not provide enough information about their beliefs toward the topic of passages in the writing task. Participants were ranged from 24 to 40 in terms of age and the mean of 29.71 years. All 
participants were Iranian students who studied English as their foreign language, and had studied English at university for at least 4 years.

\subsection{Instrument}

\subsubsection{Reading Passages}

Two reading passages with a controversial topic, child gender selection, were used in this study. Topic of passages was selected from the controversial topics of the day because it had to be controversial enough to have enough participants of both for and against groups. Since participant of this study were all adults, "child gender selection" was selected. Two reading passages were then developed with ideas from http://voices.yahoo.com. Both passages were comparable in number of words, sentences, paragraphs, syntax, sentence per paragraph, and Flesch reading ease.

Table 1. Descriptive information of two experimental passages

\begin{tabular}{lll}
\hline Category & Passage A & Passage B \\
\hline Number of words & 371 & 382 \\
Number of Paragraphs & 2 & 2 \\
Number of sentences & 19 & 21 \\
Number of words per sentence & 19 & 18 \\
Flesch-Kincaid grade level & 8.8 & 8.4 \\
Flesch reading ease & 63.9 & 64.9 \\
\hline
\end{tabular}

\subsubsection{Questionnaire}

A background questionnaire was developed to determine prior believes of participants. Prior believes of participants were determined by means of a free writing task before reading the texts to find out participants' position toward reading topic. The writing task included a question asking students' position toward the topic of readings; whether they agreed with selecting the gender of children by parents or not. 3 raters, ESL teachers with more than 5 years of experience, read participants' writings and decided whether they were for or against the topic of readings. In this study, all 3 raters agreed that 30 participants agreed with the topic of readings, child gender selection, and 26 did not. 6 participants were excluded in this part because 3 of them did not provide enough information about their believes, one just restated the question and 2 others just explained about advantaged and disadvantages and did not express their own believes.

\subsection{Procedures}

Participants read and completed a free writing task in which they were asked to write their position toward the subject of reading passages; gender selection. For this purpose, participants were required to write down their own believes and positions in a free writing task before reading the 2 passages.

After reading each of the texts, participants were asked to give back the text to the researcher, and write down as much information as they could remember from the text immediately after reading is finished, and then they were given the other passage to read and write down what they could recall from the other text. Participants were instructed to write down everything they could recall from texts, every detail and example, and they were asked not to summarize the content of the passages. There were no time limitation for recall tasks, and students had enough time to think and write down what they could remember from the texts. Since there could be a carryover effect when reading 2 passages after each other, counter balanced design was used. Participants were told that they should recall the passages they read in an immediate and a delayed recall task.

After a week, for assessing the delayed recall of participants, they were asked to write down whatever they could remember from the passages in a delayed recall task.

\section{Data analysis}

There are various methods of scoring free recall tasks in the literature. One method is to divide the text into idea units. But as Alderson (2000) mentions, there is no clear objective definition for idea units in the literature, so it is not easy to measure comprehension on that basis. Another method used for scoring readings, is Johnson's (1970) method. In Johnson's (1970) method a text is read by a native reader with natural speed, and the places that the reader pauses to breathe, is marked as a unit. In the present study, the Johnson's (1970) scoring system was used for scoring recall tasks. In this study, 3 native speakers of English were asked to read the passages, and mark where they paused in the texts.

Pausal units then were listed and 3 experienced ESL teachers in a session decided on the information value of these units. Teachers marked these units as high-level and low-level informational pausal units according to their importance in comprehending the passages. If the units contained information that helped readers to understand the meaning of the text, it was marked as high-level information unit, and if the absence of a pausal unit did not hinder the comprehension of the text, it was regarded as low-level unit. The final decision then was made on the basis of those units that all 3 raters agreed on their importance. Passage A, according to this decision, had 22 high-level, and 19 low level units, and 
passage B had 22 high-level and 24 low-level units. Then, Participants' recalls were scored. One score was given to each unit recalled correctly, and then the number of correctly recalled units was converted to percentage.

For scoring background survey of participants, 3 experienced ESL teachers read participants' writing task and decided whether the participants agreed with the subject or not.

\section{Results}

The research question investigated the impact of topic congruence on the quality of reading comprehension of 56 Iranian advanced-level EFL learners by the means of immediate and delayed recall tasks. For this purpose, the descriptive statistics were presented in Table 2. According to the background survey, 30 participants' prior believes were congruent to the topic of reading and 26 participants' background knowledge was incongruent.

Table 2. Descriptive statistics for the impact of topic congruence on quality of reading recall

\begin{tabular}{|c|c|c|c|c|c|}
\hline Variable & $\mathrm{N}$ & Minimum & Maximum & Mean & Std. Deviation \\
\hline Immediate recall-incongruent - High level information & 56 & 9.09 & 45.45 & 24.1918 & 8.00818 \\
\hline Immediate recall_incongruent -Low level information & 56 & 4.16 & 41.66 & 12.1284 & 6.58561 \\
\hline Immediate recall_congruent - High level information & 56 & 4.54 & 59.00 & 23.4339 & 9.37620 \\
\hline Immediate recall_congruent- Low level information & 56 & 4.16 & 57.00 & 11.2621 & 8.56380 \\
\hline Delayed recall_congruent -High level information & 56 & 4.54 & 59.00 & 19.4900 & 10.25114 \\
\hline Delayed recall_congruent -Low level information & 56 & 4.16 & 26.31 & 9.3457 & 5.13431 \\
\hline Delayed recall_incongruent- High level information & 56 & 4.54 & 40.90 & 20.1684 & 7.37825 \\
\hline Delayed recall_incongruent- Low level information & 56 & 4.16 & 25.00 & 8.3012 & 4.57847 \\
\hline
\end{tabular}

Note. All recall scores are given in percentages

Based on the descriptive statistics in Table 2, in immediate recall, participants whose background knowledge was incongruent with the topic of reading could recall high-level and low-level information better. In the delayed recall, participants could recall high-level information that was incongruent with their background knowledge better, but could recall low-level congruent information better than incongruent information.

Table 3. Tests of Between-Subjects Effects for the impact of topic congruence on quality of reading recall

\begin{tabular}{|c|c|c|c|c|c|c|}
\hline Source & Dependent Variable & $\begin{array}{l}\text { Type III } \\
\text { of Squar }\end{array}$ & & $\begin{array}{l}\text { Mean } \\
\text { Square }\end{array}$ & $\mathrm{F}$ & Sig. \\
\hline \multirow[t]{8}{*}{ Background } & Immediate-congruent-high level information & 339.660 & 1 & 339.660 & 4.080 & .048 \\
\hline & Immediate_congruent low-level information & 346.744 & 1 & 346.744 & 5.079 & .028 \\
\hline & Immediate_incongruent - high level information & 57.282 & 1 & 57.282 & .891 & .349 \\
\hline & Immediate_incongruent - low-level information & 15.112 & 1 & 15.112 & .344 & .560 \\
\hline & Delayed_congruent - high level information & 262.874 & 1 & 262.874 & 2.573 & .115 \\
\hline & Delayed_congruent low-level information & 143.187 & 1 & 143.187 & 5.917 & .018 \\
\hline & Delayed_incongruent - high level information & 17.097 & 1 & 17.097 & .310 & .580 \\
\hline & Delayed_incongruent- low-level information & 25.072 & 1 & 25.072 & 1.200 & .278 \\
\hline
\end{tabular}

The value of the sig. in test of between-subjects effects (Table 3) for immediate recall of congruent high-level information was 0.048 , for immediate recall of congruent low level information was 0.028 , and for delayed recall of congruent low-level information was 0.018 . These values are less than 0.05 , so it can be said that congruent topics have significant effect on immediate recall of high-level and low-level information and on delayed recall of low-level information of Iranian advanced EFL learners. The values of sig. in the Table 3 (test of between-subjects) for immediate recall of incongruent high and low-level information, delayed recall of incongruent high and low-level information, and for delayed recall of high-level congruent information are more than 0.05 ; therefore, it can be said that the effect of incongruent topics on immediate and delayed recall of high and low-level information and the effect of congruent topics on delayed recall of high-level information are not statistically significant. 
For incongruent topics, the outcome of quantitative results for this research question revealed that incongruent topics did not statistically affected immediate and delayed recall of participants for both high and low-level information.

For congruent topics, it was found that congruent topics statistically affected the immediate recall of both high and lowlevel information, but this effect was detrimental. Participants could recall less information in immediate recall of congruent information. The result show that information presented in congruent readings did not attract participants' attention as much as information of incongruent readings. In contrast, in delayed-recall task, results showed that lowlevel information in congruent topics were significantly better recalled.

The result showed that congruency of reading topics can affect the reading comprehension of L2 advanced learners. As the research outcome revealed, incongruent topics were better recalled in immediate recall and for high-level units in delayed recall, although the effect was not statistically significant. It can be interpreted that readers read ideas which are not similar to their prior believes more carefully, or incongruent topics were more interesting for readers and attracted their attention more to more important idea unit and details in immediate recall. Readers may read incongruent texts more attentively to be able to defend or analyse their own views.

Various studies on the effect of attitude on memory found that congruent information has positive effect on memory, because human memory is selective in recalling and selects congruent information to pay more attention to and recall better (Feather; 1969, Eagly, Chaiken, Chen, and Shaw-Barnes; 1999, Maplass, 1969; Read, and Roberts, 1985). But in the present study in L2, results of immediate recall showed that participants recalled incongruent information better than congruent information. This contradiction can be justified by Roberts' (1985) claim that the way people learn, or the way they pay attention to information they read can affects their recall. He argued that in natural environment people acquire information, but in classroom and in research studies, participants are asked to pay attention to information, which is different from acquiring. This justification is especially true for L2 learners who learn the language and do not acquire it like L1 participants. Therefore, the result of studies in L1 may not be applicable to L2 contexts.

Lee (2009) found that L2 learners over looked low-level information of congruent topics in their immediate recall. His finding is in line with the result of this study. This ignoring of congruent low-level information might be due to the lack of attractiveness and newness participants find in details of congruent topics. When reading congruent topics, readers read information that they already have information about and may have read about that information before, so congruent texts may not attract readers' attention as much as new challenging information; therefore, this may cause readers to ignore familiar details.

Lee's (2009) finding of congruent high-level information, in immediate recall tasks, is in contrast with the result of the present study. He found that congruent topics did not affect immediate recall of high-level information, but in this study it was found that readers could recall less high-level information when they read congruent texts. This contradiction in results may be due to the amount of knowledge participants had about the topic presented in the studies to them. According to Wiley (1995), reading recall is affected by how knowledgeable a person is. He believed that if readers are less knowledgeable about the topic they read, in recall tasks, they use more personal attitudes to help them to recall the text; therefore, more congruent information will be recalled by less expert readers.

In the present study, participants could recall incongruent information more than congruent information. Eagly, Kulesa, Chen, and Chaiken (2001) rejected the belief that people tend to ignore incongruent information. They believed that people read incongruent information even more carefully, and tried to recall them better to be able to use the information to defend their own ideas better.

\section{Conclusion}

The present study sought to investigate the impact of congruent topics on the quality of reading comprehension of Iranian advanced -level learners.

Result of this study revealed that congruent topics had significant effect on immediate recall of both high-level and lowlevel information and on delayed recall of low-level information of Iranian advanced EFL learners. It was found that information units in texts with congruent topics were less recalled in immediate recall in comparison with incongruent topics. In delayed recall tasks, the findings showed learners with congruent prior belief were more successful in recalling low-level information units.

Results also revealed that although incongruent topics were better recalled than congruent topics, this effect was not significant. Therefore, it can be said that incongruent topics do not affect immediate and delayed recall of Iranian advanced-level language learners.

\section{Implications}

Studies examining topic variables could be specifically helpful for teachers and educators in L2, and make them aware of factors that may affect comprehension and assessments of readings. These studies can also be helpful to develop more reliable tests and better teaching materials, especially in ESP/EAP contexts that learners read passages that may not be consistent with their pre-existing belief system.

In this study, it was found that congruent topics have impact on immediate recall of learners, so test developers who are developing tests to measure language ability of learners should choose topics that are not too controversial for learners because participants' prior belief may affect the recall of idea units of readings and the language assessment may not be accurate. 
Results also indicated that congruent topics affected both immediate and delayed recall of low-level information. So learners should be aware that while reading texts that are congruent to their prior belief they may pay less attention to the low level information of the text and that may affect the comprehension and recall of readings, and teachers should allocate more time to attracting learners attention to low-level information while teaching texts with congruent topics.

It was found that congruent topics have detrimental effect on readers' reading recall. Material developers should be more careful in choosing too controversial reading topics, for they may affect learners' comprehension and hinder language learning.

\section{References}

Alderson, J. C. (2000). Assessing reading. Cambridge, England: Cambridge University Press.

Asher, S. R., Hymel, S., \& Wigfield, A. (1978). Influence of topic interest on children's reading comprehension. Journal of Reading Behavior, 10, 35-47.

Bartlett, F. C. (1932). Remembering: A study in experimental and social psychology. London: Cambridge University Press.

Carrell, p. L., \& Eisterhold, J. C. (1983).Schema theory and ESL reading pedagogy. TESOL Quarterly, 17(4), 553-573.

Carrell, P. L., \& Wise, T. E. (1998). The relationship between prior knowledge and topic interest in second language reading. Studies in Second Language Acquisition, 20, 285- 309.

Chang, Y.-F. (2006). On the use of the immediate recall task as a measure of second language reading comprehension. Language Testing, 23, 520-543.

Eagly, A. H., Chen, S., Chaiken, S., \& Shaw-Barnes, K. (1999). The impact of attitudes on memory: An affair to remember. Psychological Bulletin, 125, 64-89.

Eidswick, J. (2010). Interest and prior knowledge in second language reading Comprehension, JALT Journal, 32(2). 149-168.

Farhadi, H, Ja'farpour, A. J., \& Birjandi, P. (2006).Testing Language Skills: From theory to practice. Tehran, Iran; Samt publication.

Feather, N.T. (1969). Attitude and selective recall. Journal of Personality and Social Psychology, 12, 310- 319.

Fletcher, J., (2006). Measuring reading comprehension. Scientific Studies of Reading, 10(3), 323-330.

Grabe, W. (1991). Current developments in second language reading research. TESOL Quarterly, 25 (3), 375-406.

Hudson, Th. (1991). A content comprehension approach to reading English for science and technology. TESOL Quarterly, 25(1), 77-104.

Johnson, R. E. (1970). Recall of prose as a function of the structural importance of linguistic units. Journal of Verbal Learning and Verbal Behavior, 9, 12-20.

Kobayashi, \& H., Rinnert, C. (1996). Factors affecting composition evaluation in EFL context; Cltural rhetorical pattern and readers background. Language learning. 46(3), 397-437.

Lee, S. K. (2009). Topic congruence and topic interest: How do they affect second language reading comprehension? Reading in a Foreign Language, 21(2), 159-178.

Malpas, S., (1965). Effects of attitude on learning and memory: The influence of instruction- induced sets. Journal of Experimental Social Psychology, 5, 441-453.

Read, S. J., and Rosson, M. B. (1982). Rewriting history: The biasing effects of beliefs on memory. Social Cognition, $1,240-255$.

Reutzel, D. R., and Hollingsworth, R. M. (1991). Investigating topic-related attitude: Effect on reading and remembering text. Journal of Educational Research, 84, 334-344.

Roberts, J. V. (1985). The attitude-memory relationship after 40 years: A meta-analysis of the literature. Basic and Applied Social Psychology, 6, 221-241.

Wiley, J. (1995). Are experts unbiased? Effects of knowledge and attitude on memory for text. Proceedings of the Seventeenth Annual Conference of the Cognitive Science Society, 283-286.

Wolf, D. (1993). A comparison of assessment tasks used to measure FL reading comprehension. The Modern Language Journal, 77, 473-489. 


\section{Appendix 1}

\section{Gender Selection (A)}

There are advantages and disadvantages to gender selection. Many people would argue that it's not up to a couple to decide the gender of their children, but others argue that gender selection is important.

Supporters of gender selection believe that couples should be allowed to choose the genders they feel they are well suited to raise. Many couples want two or three children, and most want at least one girl and one boy. With gender selection, this is possible. Once, I was waiting at the doctor's office in front of a woman who was pregnant with her sixth son. She was so disappointed because she had five boys and they tried one last time for a girl, and she ended up with another son. I admit that I felt sympathy for her. One other lady became depressed throughout her pregnancy because she knew she was having a boy. She really did not want to have a son and prior to his birth she suffered from depression over having a boy. Another lady that I know gave birth to a son that she thought would be a girl. She was so distraught over having a son that she refused to hold him until she left the hospital and had to. Knowing the gender of children in advance will prevent such problems. Gender selection is also advantageous when preparing for the new baby. It is very helpful for parents to know what their child's gender is when they want to buy clothes, toys, or other thing, for example for couples that have children close together, it could be economically advantageous to have the same sex close together; for example the new baby could have the older child's hand me downs. Supporters believe that gender selection would also give parents a sense of empowerment by having control over the number of children they have. Also for parents who chose their child's gender beforehand there is a shared decision between spouses. It makes a closer bind between parents which is finally better for family life of both parents and children. Supporters believe that, for the mentioned reasons, gender selection should be allowed by law to help both parents and society.

\section{Appendix 2 \\ Gender Selection (B)}

There are advantages and disadvantages to gender selection. Many people would argue that it's not up to a couple to decide the gender of their children, but others argue that gender selection is important. People against this idea argue that gender selection will take God out of the equation; he will give you the children and gender that you need. By selecting the gender you think you should have, you may be circumventing possible blessings. If I had chosen my child's gender, I would definitely have preferred to have a girl first, then a boy. But, as God would have it, I had a boy first, then a girl. Now, looking back on it, I'm so thankful and grateful that I had my son first. I think it's best to leave gender selection up to God. Gender selection is also believed to be expensive. If a couple is going through fertility treatments to have children, they have the option of choosing the sex of the baby. There are high expenses for this process. This selection by parents may also bring disapproval of family and friends. Many feel that you should leave gender selection up to God, or friend and families may cause a sense of regret by expressing their ideas, which may not be the same as yours. If it's not a choice, then you will not go back and say, "Oh, I should have chosen the other way." But when the decision is up to you then sometimes regrets can creep in later. Be sure that gender selection is the best choice for your family, before making such an important and life changing decision. Parents against the idea of gender selection believe that there is an element of excitement and surprise when choosing not to determine your baby's gender. A negative family dynamic can be created by gender selection in advance. If gender selection was left up to chance, it would've been best for a certain couple to only have girls or only have boys. Parents argue that things happen in the world for reasons beyond our imagination or knowledge. For the mentioned reasons, people against the idea of gender selection believe that gender selection should be made illegal to prevent problems for families and even societies.

\section{Appendix (3)}

\section{High level information (passage A)}

1. There are advantages

2. and disadvantages

3. to gender selection

8. Supporters of gender selection believe that

12. and most want at least one girl

13. and one boy

18. who was pregnant with her sixth son

21. and they tried one last time for a girl

22. and she ended up with another son

25. became depressed throughout her pregnancy

26. because she knew she was having a boy

32. gave birth to a son that she thought would be a girl 
33. She was so distraught over having a son

38. when preparing for the new baby

39. It is very helpful for parents to know

44. for example for couples that have children close together

45. it could be economically advantageous

51. would also give parents a sense of empowerment

53. over the number of children they have

54. Also for parents who chose their child's gender beforehand

55. there is a shared decision between spouses

56. It makes a closer bind between parents

\section{Low-level information of passage $A$}

4. Many people would argue

6. to decide the gender of their children,

14. With gender selection

16. Once

17. I was waiting at the doctor's office in front of a woman

19. She was so disappointed

24. One other lady

28. and prior to his birth

30. over having a boy

31. Another lady that I know

34. until she left the hospital

35. and had to

40. what their child's gender is

43. or other thing

50. that gender selection

52 . by having control

58. Supporters believe that

59. for the mentioned reasons

\section{Appendix 4}

\section{High-level information (Gender Selection B)}

1There are advantages

2 and disadvantages

3 to gender selection

9 People against this idea argue that gender selection

10 will take God out of the equation

29 There are high expenses for this process

31 may also bring disapproval of family and friends

24 I think it's best to leave gender selection up to God

25 Gender selection is also believed to be expensive

$37 \mathrm{Oh}$, I should have chosen the other way

41 gender selection is the best choice for your family

42 before making such an important

45that there is an element of excitement and surprise

47. That's part of the joy of preparing for the baby

48 , the element of surprise

49 A negative family dynamic 
51 If gender selection was left up to chance

54 Parents argue that things happen in the world for reasons beyond our imagination

58 believe that gender selection should be made illegal in all societies

\section{Low-level information pausal units of passage $B$}

4 Many people would argue

5 that it's not up to a couple

6 to decide the gender of their children

11 he will give you the children

12 and gender that you need

13 By selecting the gender you think you should have

14 you may be circumventing possible blessings

15 If I had chosen my child's gender

16 I would definitely have preferred to have a girl first

17 then a boy

18 But, as God would have it

19 I had a boy first

20then a girl

21 Now, looking back on it

22 I'm so thankful and grateful

26 If a couple is going through fertility treatments

27 to have children

28 they have the option of choosing the sex of the baby

34 which may not be the same as yours

36 then you will not go back and say

40 Parents should be sure that

46 when choosing not to determine your baby's gender

50 can be created by gender selection

53 or only have boys

55or knowledge

57 people against the idea of gender selection

60 and even societies

\section{Appendix (5)}

\section{Prior belief writing task}

Full name:

$$
\text { Age..... }
$$

Date.

One of the controversial issues in many societies is whether gender selection of a child before birth should be allowed by law. There are advantages and disadvantages to gender selection. The key debate is that it is not up to a couple to decide the gender of their children, but some argue that gender selection is important both for families and society. I would like to hear your position on this issue, whether you agree with gender selection or not. You can write in English or in your native language, whichever is more comfortable. 